\title{
DE HEALER À COMMANDO: ESTEREÓTIPOS E PAPÉIS DE GÊNERO NA CONSTRUÇÃO DAS PERSONAGENS FEMININAS EM FINAL FANTASY XIII
}

\author{
Luisa Kaanan \\ Instituto de Ciências Sociais da Universidade do Minho (ICS/UMinho). Email: \\ luisa.s.kanaan@gmail.com
}

Resumo: A indústria de videojogos tem 44\% de seu público composto de mulheres, conforme a Entertainment Software Association (2015), mas na lista dos jogos mais vendidos há apenas uma mulher como protagonista. Este artigo busca compreender o modo como as personagens femininas são construídas e representadas no RPG Final Fantasy XIII e em que medida este processo se articula com a veiculação de estereótipos e papéis tradicionais de gênero. Os dados foram coletados a partir de 50 horas jogadas pela autora deste estudo, com apoio de sites oficiais, de fãs e do manual do jogo. A avaliação foi feita através da análise de conteúdo à luz de uma revisão bibliográfica sobre videojogos e dos estudos de gênero. $\mathrm{O}$ estudo apontou que as personagens femininas tendem a ser construídas a partir das categorias sexuais, refletindo estereótipos e papéis de gênero tradicionais.
Palavras-chave: videojogos, personagens femininas, estereótipos de gênero, papéis sociais.

Abstract: Video game industry has already $44 \%$ of its public composed of women, according to the Entertainment Software Association (2015), but the bestseller games list shows only one female protagonist. This paper seeks to understand how female characters have been constructed and represented in Final Fantasy XIII RPG and to what extent this process has been articulated with the transmission of stereotypes and traditional gender roles. To collect data, the author of this study has played the title for 50 hours, with the support of the official and fan sites and the game's manual. Content analysis was the chosen method to treat the data that was subsequently analysed in the light of a literature review of videogames and gender studies. The study has found that the characters tend to be constructed 
according to its sexual category reflecting stereotypes and traditional gender roles.

Keywords: videogames, female characters, gender stereotypes, social roles.

\section{Introdução}

A indústria de videojogos é uma das que mais tem se desenvolvido nos últimos anos e é cada vez mais heterogénea em seu público. Dados do relatório Essential Facts About Computer and Video Game Industry, feito pela Entertainment Software Association $^{1}$ (ESA, 2015), revelam que os EUA já somam 155 milhões de jogadores/as. As mulheres representam $44 \%$ do público total, enquanto os homens correspondem a 56\% (ESA, 2015).

No entanto, a indústria não alterou a sua forma de produção, nem a imagem que faz do seu público-alvo e vem apostando em fórmulas já testadas, como sequências de jogos que fizeram sucesso, publicando, dessa forma, pouco conteúdo original (Newman, 2004;

\footnotetext{
${ }^{1}$ A ESA reúne 31 estúdios de criação de jogos, representando-os em nível federal nos Estados
}

Nieborg, 2011). As receitas utilizadas na construção dos videojogos ainda têm como foco um "hardcore gamer", adolescente, homem e americano/asiático que teria preferência por core games (i.e., aqueles com melhores gráficos e necessidade de maior dedicação ao jogo), excluindo das suas preocupações de produção mulheres e pessoas de diferentes etnias, que já são boa parte de sua audiência (Fron et al, 2007).

No ranking dos 40 jogos mais vendidos de 2014 e de 2015 (20 para computador e 20 para console) da ESA, há poucos títulos inéditos (a grande maioria é sequência de jogos já lançados) e entre eles há apenas uma mulher como protagonista (13 jogos têm homens protagonistas). Nos restantes jogos, as personagens femininas e masculinas são opcionais (jogos de luta e RPGs em que se pode construir a personagem condicionada à raça escolhida), bem como se encontram ainda jogos sem personagem protagonista.

As mulheres nesta indústria desenham um caminho que parte de uma

Unidos e é responsável pelo maior evento mundial de videogames, a Electronic Entertainment Expo (E3). 
invisibilidade inicial para a veiculação de representações ancoradas em estereótipos tradicionais de feminilidade. Embora inúmeros estudos tenham levado em consideração a presença de personagens femininas e priorizado a análise de sua representação gráfica (e.g., Burgess et al. 2007; Jansz e Martis 2007; Martins et al. 2009; Vermeulen et al. 2011; Dill e Thill, 2007), a forma como as personagens foram desenvolvidas ao longo da trama de cada game não tem sido explorada. Neste sentido, este artigo busca analisar não apenas a representação física das personagens femininas, mas procura também compreender o modo como as personagens femininas são construídas e representadas na narrativa e em que medida este processo se articula com a veiculação de estereótipos e papéis tradicionais de gênero.

O jogo escolhido para este estudo, que foi auscultado à luz da Análise de Conteúdo, foi o RPG Final Fantasy XIII porque este esteve entre os vinte mais vendidos após seu lançamento (ESA, 2011: 9) e foi o primeiro a iniciar uma nova fábula com uma protagonista mulher depois de seis títulos anteriores com personagens masculinas à frente das tramas (a última protagonista feminina foi Terra Branford em FF VI, lançado em 1994; a franquia está atualmente no título XV). Além disso, os RPGs são o terceiro gênero de jogo mais vendido para computador, o quarto para console (ESA, 2015) e os que têm mais traços narrativos focados no desenvolvimento das personagens (Zagalo, 2009; Newman 2004; Sheldon, 2004).

\section{De que são feitos os videojogos?}

De acordo com Koster (2005) e Zagalo (2009), os videojogos são arte, transmitindo ensinamentos sobre a realidade e a sociedade em que se vive (Pérez-Latorre, 2012). Autores como Jenkins (2006), Zagalo (2009) e Newman (2004) apontam que os videojogos, para passarem suas mensagens e motivarem as pessoas a jogar, apoiam-se na identidade projetada ou na deslocação somática (i.e., capacidade dos games de "transportar" quem joga para o lugar do jogo). Quem faz essa ligação é a personagem protagonista da ação, o PlayerCharacter (PC), que conecta a pessoa que joga à história desenvolvida no videojogo. Sendo um aspeto essencial da 
identidade projetada, a protagonista terá de ser uma personagem interessante e com a qual os/as jogadores/as possam se identificar e se sintam confortáveis ao assumir aquela persona (Isbister, 2006; Jorgensen, 2010).

Em conjunto com o ambiente e a interatividade, as personagens constituem uma das três camadas que compõem um videojogo (Zagalo, 2013). Estas são veículos centrais de expressão, uma vez que conduzem a ação do game e a interação do/a jogador/a com o mesmo, bem como atuam no sentido de despoletar a emoção durante o jogo. Todas as referidas camadas são criadas a partir da imaginação de seus/suas desenhadores/as, que têm na computação gráfica uma extensão da mesma (Zagalo, 2009: 118). Nesse sentido, Jenkins (2006) afirma que, dentro do "círculo mágico" em que o jogo está inserido, quem joga deixa para trás uma série de restrições sociais para tomar para si uma outra série de restrições impostas pelo jogo, tais como a necessidade de explorar o mundo do jogo com as habilidades de um duende ou a obrigatoriedade de "matar" alguém para passar de fase. A respeito das regras criadas pelos/as game designers para cada jogo e sua correspondência com a realidade, Newman afirma que:

$$
\begin{aligned}
& \text { Because the characteristics and } \\
& \text { properties of these constructed } \\
& \text { videogame cyberspaces do not, and } \\
& \text { indeed cannot, exist 'innately' as } \\
& \text { constituents of the gameworld but } \\
& \text { must be coded as elements in the } \\
& \text { simulation, there is no need for } \\
& \text { slavish correspondence to the 'laws' } \\
& \text { of offline, 'geographic' space (2004: } \\
& 110) \text {. }
\end{aligned}
$$

Assim, os/as desenhadores/as de jogos são quem define as regras às quais se submetem os/as jogadores/as, fazendo-o a partir das suas próprias subjetividades (Newman, 2004; Kuittinen \& Holopainen, 2009). Newman (2004) e Levis (1997) apontam que a tendência é, dessa forma, reproduzir valores dominantes da sociedade, pois o conjunto de designers - em sua maioria homens - compõe os jogos de acordo com as suas próprias preferências. Jenkins (2006) aponta que os/as desenhadores/as de jogos têm gradativamente percebido as suas responsabilidades éticas na criação de videojogos em relação ao conteúdo produzido, pelo que é necessário que a indústria repense o uso da violência e busque rever os valores vigentes. 


\section{Videojogos e construção de personagens}

O desenho das personagens não se refere meramente às escolhas estéticas feitas pelo/a criador/a; ao invés, vai além da simples representação gráfica de uma figura e inclui a definição da sua personalidade, características, atitudes e forma (e.g., se tem aspeto humano, animal ou de figuras geométricas). A criação da personagem pode ser facilitada quando se entende qual é a sua função na história, pois é necessário assegurar a coerência entre a representação gráfica e a mensagem que se pretende transmitir (Teixeira, 2013).

$\mathrm{Na}$ construção das personagens para videojogos, Sheldon (2004) e Isbister (2006) revelam que o uso de estereótipos é comum, pois facilita o entendimento da personagem e reduz o tempo da sua produção. Porém, Sheldon argumenta que uma personagem estereotipada é pouco valorizada e que "for the most part, stereotypes work against the veracity of the narrative. Since they are so common, we don't notice them" (2004: 57-58). Jorgensen (2010) sugere que as personagens devem ter um passado bem fundamentado (backstories) e um desenvolvimento ao longo da trama para se tornarem interessantes (do ponto de vista da originalidade) e profundas (do ponto de vista da complexidade psicológica e emocional) e, assim, favorecerem uma subversão de estereótipos.

Para uma personagem ser bem definida e complexa, Sheldon (2004) sublinha que é necessário que esta contemple três dimensões: a física, a sociológica e a psicológica. A primeira a dimensão física - engloba os traços visíveis (e.g., tamanho, sexo, raça, rosto, gestos corporais e roupas) que, segundo Isbister (2006), influenciam o modo como a personagem é percebida (e.g., amigável, desafiadora, inimiga, submissa). Depois, a dimensão sociológica corresponde ao passado (i.e., as backstories, escolhas feitas antes do início do jogo), ao momento presente (relativo ao momento do jogo em que a personagem se encontra e às atitudes tomadas ao longo da trama) e aos traços culturais, que dizem respeito à origem da personagem. Por fim, a dimensão psicológica refere-se à personalidade da personagem, sendo esta percebida através das suas ações, atitudes e forma como encara o mundo. 
Videojogos e (assimetrias de) gênero

Em uma indústria na qual o público-alvo engessou-se em homens adolescentes para produzir seu conteúdo, importa refletir sobre as fantasias que são oferecidas para as mulheres como motivação para jogar. Conforme o estudo de Vermeulen et al. (2011), as mulheres preferem jogar com personagens do mesmo sexo/gênero e se incomodam com imagens femininas sexualizadas. A respeito dos jogos female-friendly, Isbister (2006) destaca que estes devem levar em consideração os estilos de jogo femininos (que seriam definidos a partir de estereótipos associados a este gênero, tais como a tendência a criar em vez de destruir), o que para Fron et al (2007) seria considerar diferentes estilos de jogo além do padrão hegemônico (que é o dito masculino).

A definição de um jogo amigável para as mulheres, os hábitos de jogo das jogadoras e as personagens oferecidas para as mesmas podem ser melhor compreendidos se levarmos em conta os contributos dos estudos de gênero. Segundo Bonvillain (1995), o gênero é um aspeto primário na vida e na identidade de cada pessoa, constituindo um elemento central na organização do cotidiano (Gill, 2010). Para Amâncio (1998), a assimetria na construção do "masculino" e do "feminino" mostra uma estratificação de grupos de origem ideológica. A ideologia dominante torna-se invisível porque é traduzida em senso comum, é naturalizada (Van Zoonen, 2006).

A partir daí, os estereótipos podem ser entendidos como um conjunto de características baseadas num sistema de valores individual e coletivo e de ideologizações coletivas acerca dos comportamentos, bem como são uma forma de seleção de dados que facilita e simplifica a informação social (Amâncio, 1998). Em relação aos estereótipos de gênero, Cerqueira (2008: 139) afirma que "o feminino enquanto construção social implica uma clara distinção entre sexo e gênero", tendo em vista que o sexo é a função biológica e o gênero é uma construção ideológica que pressupõe comportamentos e expectativas. Os papéis sociais de gênero, que são amplamente difundidos pelos agentes ideológicos de socialização (e.g., mídia), podem ser pensados como normas de conduta das categorias sexuais baseadas nesse 
sistema de valores partilhado e articulado com os estereótipos que dizem respeito ao comportamento e ao modo de ser de homens e mulheres (Amâncio, 1998).

No seu estudo com trabalhadores/as e estudantes portugueses/as, Amâncio (1998) mostra que os traços associados ao estereótipo feminino estão relacionados à beleza, à emotividade, à sensibilidade e à fragilidade (i.e., características globalmente consideradas negativas), enquanto ao estereótipo masculino estão atribuídas a força, a dominância e a independência (i.e., dimensões acolhidas genericamente como positivas). Tendo em conta as características atribuídas ao estereótipo masculino, este emerge como um modelo de pessoa autônoma e determinada, assim como apresenta uma maior variedade de comportamentos socialmente aceitos. Por conseguinte, os traços atribuídos aos homens legitimam a sua autoridade em diversos contextos (e.g., laborais), ao passo que as características associadas ao estereótipo feminino forçam a escolha entre a identidade feminina e a perda das qualidades instrumentais.

\section{Metodologia}

No presente estudo, utilizou-se uma revisão bibliográfica sobre as formas de criação de personagens para videojogos, bem como as teorias sobre esse tipo de mídia em conjugação com os contributos provenientes dos estudos de gênero para embasar a análise dos estereótipos e dos papéis sociais veiculados nos videojogos. Optou-se, para a coleta de dados, por jogar o "RPG Final Fantasy XIII" durante 50 horas com apoio de walktroughs, gameplays e do manual do jogo, que foram usados de forma a acelerar o curso do game sem deixar detalhes relevantes fora da análise (Zagalo, 2009; Newman, 2004). Os dados obtidos foram avaliados através da Análise de Conteúdo porque esta oferece a possibilidade de cruzar avaliações qualitativas e quantitativas que permitem a descrição e a interpretação dos dados (Bardin, 1977; Cerqueira, 2008). As personagens foram analisadas de acordo com as categorias física, psicológica e sociológica.

No que concerne à primeira categoria, os aspetos corporais (e.g., rosto, movimentos, roupas, tamanho corporal, espaço ocupado e olhar) dão pistas sobre o poder social e a 
personalidade da personagem (Isbister, 2006), assim como ajudam no processo de perceção da mesma (Teixeira, 2013). O formato do rosto, o corpo e os respetivos gestos apontam traços de dominância/submissão amigabilidade/inamigabilidade: por exemplo, uma personagem que ocupa muito espaço e/ou faz movimentos lentos tende a ser mais dominante e desafiadora do que uma outra que ocupe menos ou se movimente de forma rápida e nervosa. Um rosto com traços de bebê é mais atrativo e desperta sentimentos de proteção; porém, “A baby face character is not an appropriated choice, for example, for getting the player to feel extremely dominant and competent" (Isbister, 2006: 16). Traços de bebê remetem ainda à fragilidade associada ao estereótipo feminino (Teixeira, 2013). A profissão é também uma das características físicas que pode descrever personagens sem muitas apresentações (Sheldon, 2004). A categoria "habilidade" é "the bedrock of the development of the player-character" (Sheldon, 2004: 94) e, conforme Newman (2004), é, por vezes, mais importante do que sua personalidade, pois para explorar o mundo do jogo é preciso ter as capacidades necessárias.

A categoria psicológica, conforme Gancho (1998 apud Teixeira, 2013), é relativa à personalidade da personagem que, para Isbister (2006), corresponde à forma como se leva a vida. Cinco traços de personalidade se mantêm estáveis através das culturas e são conhecidos por OCEAN - Openness, Conscientiousness, Extroversion, Agreeableness e Neuroticism (McCrae e Costa, 1987 apud Isbister, 2006: 35). A Openness (abertura para o jogo/coragem), a Conscientiousness (atos baseados em planejamento ou impulso) e o Neuroticism (altos e baixos emocionais) só são percetíveis com o convívio (Isbister, 2006), ao passo que a Extroversion e a Agreeableness podem ser percebidos através dos traços físicos somados ao comportamento do corpo (e.g., sorriso, postura e espaço ocupado). Para este estudo, será destacado o traço Agreeableness (i.e., comportamento com o corpo em relação à outra pessoa), uma vez que remete a dois aspetos: dominância/submissão e a amigabilidade/inamigabilidade. Nesta categoria, ações como sorrir, abraçar/tocar e curvar-se indicam 
amigabilidade/dominância. Conforme Davis (1999: 97 apud Zagalo, 2009: 325), cada tipo de toque significa uma emoção: palmadinhas nas costas sugerem amizade; abraços e tapinhas na cabeça supõem afeto.

$\mathrm{Na}$ categoria "personalidade", serão usados como base para a caracterização das personagens os resultados encontrados por Amâncio (1998) em seu estudo que, conforme referido, apontou dimensões associadas aos estereótipos feminino e masculino. Em relação ao estereótipo feminino, a afetuosidade, a beleza, o carinho, a elegância e a sensibilidade surgem como aspetos positivos; a dependência, a fragilidade e a submissão são classificadas como aspetos negativos; a emotividade, a feminilidade, a maternalidade, o caráter romântico e o sentimentalismo surgem como aspetos nem positivos nem negativos. Quanto ao estereótipo masculino, os traços positivos associados incluem a audácia, a coragem, a desinibição, o carácter de empreendedor, a força, a independência e a seriedade. Os aspetos classificados como negativos correspondem à desorganização e ao caráter de dominador, ao passo que a ambição, o autoritarismo, o espírito de aventura, o machismo, o paternalismo, a rigidez, a superioridade e a virilidade aparecem sem classificação (Amâncio, 1998:63).

$\mathrm{Na}$ categoria sociológica, Sheldon (2004) inclui o passado, a cultura e o contexto em que a personagem viveu antes do que se passa no jogo. São essas histórias anteriores (backstories), segundo Jorgensen (2010), que dão profundidade e complexidade à personagem. As backstories e a personalidade devem transparecer na aparência, no jeito de andar e falar da personagem. Nesta categoria, está ainda o presente da personagem, que se refere às atitudes que esta toma durante o jogo e que são consequência do passado, bem como os traços culturais atribuídos a ela (Teixeira, 2013).

A tabela 1, utilizada na pesquisa de mestrado de Kanaan (2015), sintetiza as categorias referidas. 
Tabela 1 - Dimensões Constitutivas das Personagens (Kanaan, 2015: 44)

\begin{tabular}{|l|l|l|}
\hline Física & Psicológica & Sociológica \\
\hline Raça & Personalidade & Passado \\
\hline Sexo & Openness & Presente \\
\hline Habilidades & Conscientiousness & $\begin{array}{l}\text { Traços culturais (aspetos } \\
\text { sociais) }\end{array}$ \\
\cline { 1 - 2 } Corpo (e seu uso) & Extroversion & \\
\cline { 1 - 2 } Rosto (e partes integrantes) & Agreeableness & \\
\cline { 1 - 2 } Voz & Neuroticism & \\
\cline { 1 - 2 } Olhar & \multicolumn{2}{|l|}{} \\
\hline
\end{tabular}

Durante a descrição de cada personagem, buscou-se perceber se estas apresentavam traços associados aos estereótipos de gênero e aos papéis sociais tradicionais apontados por Amâncio (1998). Os estereótipos foram incluídos na categoria psicológica "personalidade" porque, conforme a autora, referem-se às características e aos modos de ser das pessoas, o que coincide justamente com as definições de personalidade incluídas por Isbister (2006) e Teixeira (2013) na categoria psicológica. Os papéis sociais foram analisados na categoria sociológica "presente" porque, ainda de acordo com Amâncio (1998), são normas de conduta e, por isso, remetem à ação que as personagens tomam na narrativa. Em relação à categoria física, como foi apresentado anteriormente, ela é mais do que uma opção estética, pois representa visualmente a conjunção das categorias psicológicas e sociológicas, assim como a função da personagem na trama. Assim, os diversos aspetos englobados nesta categoria serão analisados de forma a ver se apresentam traços associados aos estereótipos de gênero.

\section{Objeto de estudo}

A franquia Final Fantasy é um conjunto de videojogos de Role Playing Game japonês (JRPG), produzida por Hironobu Sakaguchi e desenvolvida pela 
Square Enix, com início em 1987 no Japão (em 1990, nos EUA). A franquia existe há 29 anos e tem 15 títulos principais (lançados até 2016, sem contar spin-offs, sequências e outros produtos com o nome Final Fantasy).

Final Fantasy XIII (FFXIII) foi lançado mundialmente em 2010 (2009, no Japão) com um enredo mais focado na história das personagens, apresentadas em 13 capítulos. Apesar de ter sido criticado pela sua linearidade, o título vendeu 5,1 milhões de cópias desde seu lançamento até abril de $2015^{2}$. Em 2012, o jogo ganhou a sequência "Final Fantasy XIII-2" e, em 2014, o último da trilogia "Lightning Returns: Final Fantasy XIII”.

\section{Síntese da trama do jogo}

FFXIII é um RPG de fantasia que se passa em um universo onde entidades mágicas - designadas por Fal'Cie ajudam humanos/as de dois continentes rivais (Cocoon e Gran Pulse) a viver, provendo-lhes comida e outras necessidades. Essas entidades contam com a ajuda de servos humanos -

\footnotetext{
2 http://www.vgchartz.com/game/7727/final-
} fantasy-xiii/Global/ chamados de l'cie - que são escolhidos contra sua vontade.

Ao longo de treze capítulos, conhecemos a história de seis pessoas que se unem contra um destino que lhes foi imposto pelos Fal'Cie. Lightning, Snow, Sazh e Hope, habitantes de Cocoon (que é suspenso no céu), viviam normalmente até Vanille e Fang, nativas de Gran Pulse, acordarem do estado de cristal em que se encontravam depois de terem participado como l'Cie em uma guerra ocorrida entre os dois continentes. Esse acordar fez com que os Fal'Cies transformassem em servos entes queridos de algumas personagens, designadamente a Serah, irmã de Lightning e noiva de Snow, e o Dajh, filho de Sazh, que se transformam de seguida em cristal.

O objetivo de todos os servos é destruir Cocoon e seus habitantes. Caso não cumpram a tarefa, serão transformados em monstros para sofrer pela eternidade (os Cie'ths); se cumprirem este propósito com sucesso, serão convertidos em cristais. Decididos a não cumprir a tarefa, o grupo busca formas de resgatar Serah e Dajh e, por 
conseguinte, de impedir que eles mesmos se tornem monstros. Todavia, o grupo diverge sobre como levar a cabo este objetivo, pelo que seguem caminhos separados até ao décimo capítulo, quando se reúnem novamente. No final, o grupo acaba com o plano dos Fal'Cies e, antes de Cocoon cair do alto do céu, Vanille e Fang se tornam o cristal que segura o continente no alto.

\section{Sistema de batalha}

Em FF XIII, o sistema não é baseado em turnos, mas sim no tempo necessário para cada ação. Durante a luta só é possível controlar uma personagem (o protagonista do capítulo ou, a partir do $10^{\circ}$, o líder da equipe escolhida). As outras personagens são orientadas a partir do papel ("role") que desempenham no paradigma escolhido para a batalha. $\mathrm{O}$ jogo coloca à disposição seis papéis, mas cada personagem tem acesso, no máximo, a três até ao décimo capítulo (i.e., quando os seis ficam disponíveis). Cada papel tem habilidades específicas, a saber: Commando (ataques de contato); Ravager (ataques mágicos à distância); Sentinel (defesa da equipe, desviando para si o dano provocado pelo inimigo);
Medic (especialista em cura e em reviver aliados); Saboteur (sabota o inimigo através de veneno e outros elementos); Synergist (dá suporte e proteção à equipe, aumentando a força e a magia).

\section{Análise e Discussão}

\section{Lightning}

Conforme o manual do game e o website oficial, Lightning é uma jovem solitária que fala pouco de si mesma. Com o nome completo Claire Farron, Lightning é policial, mas suas roupas não correspondem ao uniforme comum; ao invés, são uma variação dele no qual pernas e braços estão à mostra. A personagem tem 21 anos e o fato de ser policial é apontado pelas restantes personagens do grupo como a razão de ser forte e determinada. Seu status inicial é equilibrado ao nível da magia e da força, mas ela tem o segundo mais baixo Health Point (pontos de vida), perdendo apenas para Hope, que é o mais jovem da equipe. Os papéis iniciais de Lightning são os de Commando (ataque de contato), Ravager (ataques mágicos à distância) e Medic (especialista em cura). 
Inicialmente, a personagem pretendia seguir a luta sozinha pela sua irmã, mas é convencida a acompanhar e cuidar do grupo. Lightning identifica-se com Hope - adolescente que perdeu a mãe no primeiro confronto do jogo e atribuiu a culpa a Snow pelo ocorrido por ambos buscarem vingança e ajuda-o na tarefa de ficar mais forte. Posteriormente, Lightning pede desculpas a Snow e aponta-o como herói por incentivar o grupo e nunca ter deixado de acreditar em Serah (o que teria mantido Hope e ela própria vivos, além de ter tornado o adolescente mais forte).

Esta personagem é um dos PC (i.e., a que controlamos por mais tempo; joga-se com Lightning em quase todos os capítulos, menos em dois, até ao décimo a partir do qual é possível escolher quem é a equipe de luta e o PC). Lightning pode ser considerada a protagonista, já que é através do seu ponto de vista que a maior parte dos eventos do jogo se desenrola.

Tabela 2 - Aspetos construtivos de Lightning

\begin{tabular}{|l|l|l|}
\hline Física & Sociológica & Psicológica \\
\hline $\begin{array}{l}\text { Corpo: magra curvilínea } \\
\text { Tamanho: médio } \\
\text { Movimentos: ágeis que } \\
\text { ocupam espaço médio }\end{array}$ & $\begin{array}{l}\text { Passado: perdeu os pais e } \\
\text { teve de cuidar da irmã mais } \\
\text { nova. Mudou de nome e } \\
\text { tornou-se sargento. }\end{array}$ & $\begin{array}{l}\text { Personalidade: séria, } \\
\text { corajosa, independente, } \\
\text { maternal, forte, afetuosa } \\
\text { (após determinado } \\
\text { momento). }\end{array}$ \\
\hline $\begin{array}{l}\text { Rosto: algumas } \\
\text { características de baby } \\
\text { face. }\end{array}$ & $\begin{array}{l}\text { Presente: não aceitava o } \\
\text { namoro da irmã e, depois } \\
\text { de vê-la transformar-se em } \\
\text { cristal, sente-se culpada e } \\
\text { busca vingança sozinha. } \\
\text { porém, é convencida a } \\
\text { continuar no grupo e a } \\
\text { zelar por eles. Credita } \\
\text { vitórias coletivas a Snow. }\end{array}$ & $\begin{array}{l}\text { Agreeableness } \\
\text { Corrir: pouco } \\
\text { Abraçar: siman }\end{array}$ \\
\hline $\begin{array}{l}\text { Olhar: encara outras } \\
\text { personagens. }\end{array}$ & $\begin{array}{l}\text { Traços culturais: vive em } \\
\text { Cocoon, odeial Pulse, } \\
\text { militar. }\end{array}$ & \\
\hline $\begin{array}{l}\text { Habilidade: ataques físicos } \\
\text { e magias. }\end{array}$ & \multicolumn{2}{|l}{} \\
\hline
\end{tabular}


Vanille

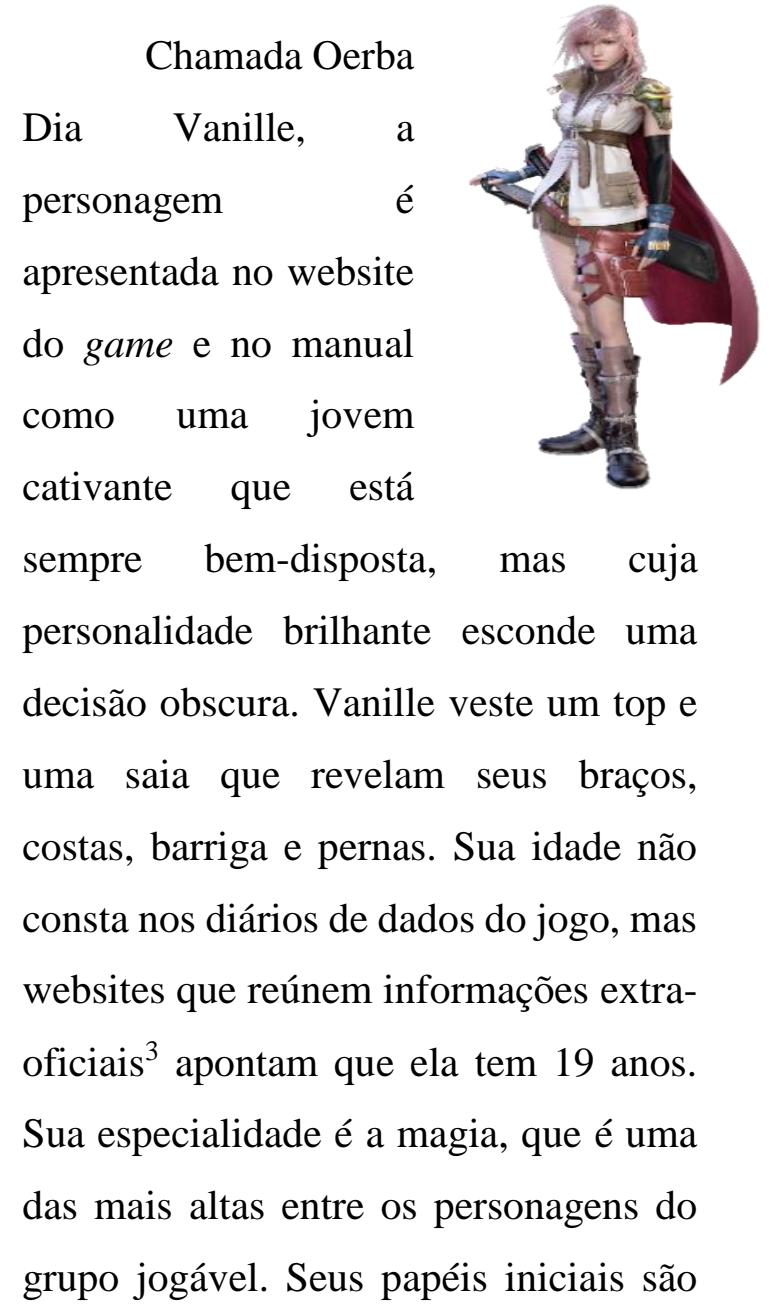

de Ravager, Medic e Saboteur, ou seja, dois papéis de luta à distância e um de cura.

A personagem sente-se culpada pelas vidas desperdiçadas quando foi l'Cie e também pelo envolvimento de mais pessoas no tempo em que o jogo acontece. Para não ter de ferir mais pessoas, como aconteceu no passado, ela foge da sua missão atual mesmo sabendo que isso pode torna-lá um Cie'th. É muito preocupada com os demais, principalmente com Fang, e encoraja-os a ter objetivos, mesmo que seja o de se vingarem dela. Apesar de estar sempre animada, Vanille é facilmente levada às lagrimas e pensa em si mesma como uma assassina e covarde. Ela tem uma natureza pacífica e está disposta a sacrificar a sua vida pelos outros.

Tabela 3 - Aspetos construtivos de Vanille

\begin{tabular}{|l|l|l|}
\hline Física & Sociológica & Psicológica \\
\hline $\begin{array}{l}\text { Corpo: magra curvilínea } \\
\text { Tamanho: pequeno } \\
\text { Movimentos: largos, } \\
\text { desajeitados e rápidos }\end{array}$ & $\begin{array}{l}\text { Passado: nasceu em Gran } \\
\text { Pulse séculos antes do } \\
\text { início do jogo e já era um } \\
\text { 1'Cie antes desses eventos. } \\
\text { Por completar seu objetivo, } \\
\text { virou cristal. }\end{array}$ & $\begin{array}{l}\text { Personalidade: emotiva, } \\
\text { afetuosa, sensível, meiga, } \\
\text { frágil, corajosa, carinhosa. }\end{array}$ \\
& & \\
\hline
\end{tabular}

3

http://www.finalfantasy.com.br/index.php?optio $\mathrm{n}=$ com_content \&view=article\&id=947\&Itemid
$=334$

http://finalfantasy.wikia.com/wiki/Oerba_Dia Vanille 


\begin{tabular}{|l|l|l|}
\hline $\begin{array}{l}\text { Rosto: muitas } \\
\text { características de baby } \\
\text { face. }\end{array}$ & $\begin{array}{l}\text { Presente: para evitar uma } \\
\text { nova guerra, mente que } \\
\text { perdeu a memória, mas isso } \\
\text { gera os eventos do jogo. } \\
\text { Sente-se culpada pelo } \\
\text { envolvimento de outros e } \\
\text { quer evitar seu objetivo } \\
\text { (destruir Cocoon) mesmo } \\
\text { que custe sua vida. }\end{array}$ & $\begin{array}{l}\text { Agreeableness } \\
\text { Sorrir: muito } \\
\text { Curvar-se: muito } \\
\text { Abraçar: muito }\end{array}$ \\
\hline $\begin{array}{l}\text { Olhar: não encara outras } \\
\text { personagens. }\end{array}$ & $\begin{array}{l}\text { Traços culturais: é de Gran } \\
\text { Pulse, mas acha que os } \\
\text { continentes não precisam } \\
\text { guerrear. }\end{array}$ & \\
\hline Habilidade: magia e cura & \multicolumn{2}{|l}{} \\
\hline
\end{tabular}

\section{Fang}

A descrição desta personagem é a de uma mulher misteriosa que, apesar de ser uma l'Cie de Gran Pulse, trabalha para os militares de Cocoon. É descrita como tendo uma personalidade forte, que não está disposta a medir palavras. Chama-se Oerba Yun Fang, tem 21 anos, apresenta uma tatuagem no braço esquerdo e roupa azul que revela as pernas, a barriga e os braços. Das personagens femininas, ela é a mais alta. Fang junta-se ao grupo apenas no capítulo sete, embora apareça brevemente no capítulo dois. Demonstra um sentimento maternal em relação a
Vanille. À semelhança de Lightning, ela é independente, forte e determinada, mas é mais sarcástica e sorridente.

Fang tem o ataque mais poderoso da equipe. Seus papéis iniciais são os de Commando, Sentinel e Saboteur, ou seja, um de ataque de contato, um de distância e um de defesa (para este papel é preciso ter HP alto e só duas personagens o têm inicialmente: ela e Snow). Joga-se com Fang como Player Character no capítulo sete. 
Tabela 4 - Aspetos construtivos de Fang

\begin{tabular}{|l|l|l|}
\hline Física & Sociológica & Psicológica \\
\hline $\begin{array}{l}\text { Corpo: magra curvilínea } \\
\text { Tamanho: grande } \\
\text { ágeis }\end{array}$ & $\begin{array}{l}\text { Passado: nasceu em Gran } \\
\text { Pulse séculos antes do } \\
\text { início do jogo e já era um } \\
\text { l'Cie. }\end{array}$ & $\begin{array}{l}\text { Personalidade: forte, } \\
\text { corajosa, independente, } \\
\text { maternal, afetuosa e } \\
\text { sarcástica. }\end{array}$ \\
\hline $\begin{array}{l}\text { Rosto: poucas } \\
\text { características de baby } \\
\text { face. }\end{array}$ & $\begin{array}{l}\text { Presente: acorda em forma } \\
\text { de cristal, sem memória do } \\
\text { Focus anterior. Arma } \\
\text { estratégias para recuperar a } \\
\text { memória e completar o } \\
\text { Focus de Vanille para ela } \\
\text { não virar Cie'th. }\end{array}$ & $\begin{array}{l}\text { Agreeableness } \\
\text { Currir: sim } \\
\text { Abraçar: sim }\end{array}$ \\
\hline $\begin{array}{l}\text { Olhar: encara outras } \\
\text { personagens. }\end{array}$ & $\begin{array}{l}\text { Traços culturais: é de Pulse } \\
\text { e não se importa se tiver de } \\
\text { destruir Cocoon para salvar } \\
\text { Vanille. }\end{array}$ & \\
\hline $\begin{array}{l}\text { Habilidade: ataques físicos, } \\
\text { magias de sabotagem, } \\
\text { sentinela. }\end{array}$ & \multicolumn{2}{|l|}{} \\
\hline
\end{tabular}

A partir da análise do material coletado e acima apresentado, foi possível constatar que todas as personagens femininas de FFXIII são jovens, brancas e magras curvilíneas, e representam metade da equipe jogável, ao contrário de outros títulos da franquia onde elas são a minoria (e.g., FFX). Este fato está em consonância com a representação das mulheres na maioria dos videojogos, seguindo o caminho que outras mídias trilharam: a invisibilidade inicial deu lugar a representações enformadas pelos estereótipos tradicionais de feminilidade.

Em FFXIII, os estereótipos tradicionais estão presentes na categoria física das personagens. Enquanto nas masculinas vemos uma variedade de idades - Hope é um adolescente, Snow é um jovem adulto e Sazh é um homem de meia-idade -, as idades das personagens femininas variam apenas em dois anos: duas têm 21 anos e uma 19 anos. A idade também se reflete no rosto: as mulheres apresentam na sua maioria traços de 
bebê - duas das três personagens femininas exibem estas características. No caso das personagens masculinas ocorre o contrário: a maioria delas (duas) não aparenta quaisquer traços de bebê, tendo como composição do rosto o queixo largo, barba, nariz grande, olhos finos, sobrancelhas próximas aos olhos. Apenas Hope tem traços de bebê porque é adolescente.

Relativamente à forma como as personagens são representadas fisicamente, Vermeulen et al. (2011) cita o estudo de Millers e Summers (2007), que analisou o conteúdo de artigos em revistas de videogame, entre 2003 e 2005, referindo que os homens eram representados como personagens principais poderosas e musculosas, enquanto as mulheres surgiam como personagens subordinadas e frequentemente apresentadas como sensuais, inocentes e com vestuário reduzido. Em FFXIII, todas as personagens femininas usam justamente saias e mostram grande parte do corpo, corroborando os estudos mencionados, ao passo que todos os homens usam calças e estão quase totalmente cobertos.

\footnotetext{
${ }^{4}$ Esta classificação se deu através da análise da relação entre todos/as os/as personagens no
}

A estatura corporal das personagens femininas varia entre pequena (Vanille) e média (Lightning), sendo apenas uma delas grande (Fang). Mesmo assim, a personagem feminina mais alta é ligeiramente menor do que o homem mediano (Sazh); eles ocupam mais espaço do que elas ${ }^{4}$.

Além disso, verificou-se que apenas uma personagem feminina utiliza muito espaço para seus movimentos (Vanille), que são desajeitados e nervosos, refletindo submissão. A maioria das personagens femininas executa seus movimentos próximos ao corpo, contrariamente ao que acontece com as personagens masculinas, as quais requerem muito espaço $\mathrm{e}$, por conseguinte, maior dominância. Ainda dentro dos aspetos construtivos físicos, a profissão da maioria das personagens masculinas é conhecida (Sazh é piloto e Snow é líder de milícia), mas somente com uma personagem feminina acontece o mesmo. Contrariamente ao que ocorre com Lightning, as profissões das personagens masculinas não são referenciadas como origem de sua maior força/habilidade em determinada área.

videojogo, tomando como parâmetros o visivelmente maior (Snow) e o visivelmente menor (Hope). 
As habilidades constituem um aspeto importante na construção de personagens para videojogos, pois estas são necessárias para explorar o cenário do jogo. Neste título, todas as personagens (femininas e masculinas) têm todas as habilidades (papéis de luta) após certo momento no jogo. Há, porém, diferenças nos papéis disponíveis inicialmente para personagens femininas e masculinas e o quão satisfatoriamente elas desempenham estes papéis. Duas das três personagens femininas (Vanille e Lightning) têm o papel de Medic (i.e., poder de curar e de fazer reviver aliados), enquanto apenas um dos três homens (Hope) tem esse papel (mas sem a capacidade de reviver) inicialmente, $o$ que aponta para um papel tradicional de gênero no qual a mulher teria uma “propensão natural” (Bonvillain, 1995) para cuidar, curar e dar vida.

Entre os papéis que estão disponíveis para as mulheres de início, não se encontra o de Synergist (i.e., que faz magias de proteção da equipe); o mesmo acontece com os homens com o papel de Saboteur (que faz magias de dano ao inimigo). Eles têm o papel de proteger a equipe e elas de fazer magias de dano, remetendo ao arquétipo das bruxas e distribuindo as habilidades iniciais consoante os estereótipos de gênero. Além disso, cada personagem tem uma habilidade diferente dentro de cada papel, o que torna uns melhores do que outros durante as lutas. Destaque-se, por exemplo, que Fang e Snow podem ser Sentinel (papel de defesa), mas ele é ligeiramente melhor por ter mais pontos de vida (HP) e habilidades que não estão disponíveis para Fang. Outro exemplo é que, entre todas as personagens, Vanille é a pior Sentinel, perdendo até para Hope (que tem 14 anos e menos HP), mas é uma das melhores médicas, rivalizando também com Hope por ele desempenhar as magias de cura mais rapidamente.

No que concerne aos aspetos psicológicos, particularmente aos traços de Agreeableness, verificou-se que a maioria das personagens femininas (Lightning e Fang) não se curva e sorri pouco; apenas Vanille o faz frequentemente. Porém, todas as personagens femininas abraçam as restantes, enquanto o máximo de contato entre os homens são palmadinhas. Vanille não endereça um olhar direto, ao passo que Lightning e Fang parecem estar confortáveis encarando, 
demonstrando-se dominantes nessas situações.

Lightning apresenta quatro dimensões atribuídas convencionalmente ao estereótipo masculino (i.e., seriedade, coragem, independência e força) e dois ao estereótipo feminino (i.e., afetuosidade e sentimento maternal); Fang manifesta três características ditas masculinas (i.e., coragem, independência e força) e como qualidades femininas a afetuosidade e o sentimento maternal ${ }^{5}$; e Vanille apresenta cinco aspetos ditos femininos (i.e. emotividade, afetuosidade, sensibilidade, fragilidade e carinho) e um masculino (i.e., coragem). Neste sentido, as características associadas ao masculino que aparecem com maior frequência nas personagens femininas são a coragem, a independência e a força (Lightning e Fang), enquanto Vanille reúne a maioria dos traços ditos femininos (sensibilidade e emotividade). Lightning e Fang são, pois, as "duronas" mas que, mesmo assim, apresentam traços de afeto e cuidado para com os membros do grupo.

\footnotetext{
${ }^{5}$ Escolheu-se o termo maternal para caracterizar a expressão afetiva de Lightning e Fang. A primeira personagem é impedida de deixar Hope para trás e seguir seu caminho sozinha; Hope,
}

106

Enquanto a afetuosidade é uma característica comum entre as personagens femininas, esta não se revela entre as personagens masculinas. Por conseguinte, estas últimas apresentam poucas características associadas ao estereótipo feminino: Snow não apresenta traços ditos femininos; Sazh tem um instinto maternal em relação aos membros do time; Hope tem quatro características ditas femininas (dependência, fragilidade, emotividade e sensibilidade) em seu perfil até metade do jogo e, posteriormente, "amadurece" e deixa de apresentar dois dos traços associados ao estereótipo feminino que foram apontados como negativos (fragilidade e dependência). No caso de Sazh, ele teve de assumir o papel de "mãe" de Dajh porque sua esposa morreu, o que sugere que apenas na ausência da mãe é permitido ao pai cuidar do filho.

A partir da análise das ações das personagens durante o jogo, verificou-se uma distribuição de traços dos estereótipos feminino e masculino entre as personagens analisadas. Todavia, os

dormindo, percebe a aproximação de alguém (no caso Lightning) e pensa ser sua mãe. Fang referese a Vanille como família e cuida dela de forma maternal. 
traços do estereótipo feminino retratados em um personagem masculino foram maioritariamente negativos, enquanto os traços masculinos retratados em personagens femininas foram positivos. As características do estereótipo masculino se fazem maioritariamente presentes entre todas as personagens, $o$ que corrobora a posição de Amâncio (1998: 169), segundo a qual o estereótipo masculino é um exemplo para homens e mulheres, enquanto os traços femininos só servem para as próprias mulheres e em contextos definidos.

Em relação à categoria sociológica, o passado das personagens femininas é geralmente pouco conhecido, o que não contribui para a subversão de estereótipos (Jørgensen, 2010). Sabemos que Lightning é órfã, policial e responsável pela irmã; contudo, sobre Fang e Vanille, não se sabe o que faziam antes de se terem tornado l'Cie. Pelo contrário, no caso das personagens masculinas, há um maior detalhamento do passado: por exemplo, a história de Snow é referida claramente - sabe-se que é órfão, cresceu com amigos (os quais são conhecidos), seus planos para o futuro e até o seu bar favorito são mencionados.

No "presente" das personagens femininas, importa ressaltar que há uma personagem feminina - Vanille - que está disposta a sacrificar-se pelos/as restantes, o que é consonante com as dimensões da feminilidade normativa (Van Zoonen, 2006) e não acontece com nenhum dos homens. Duas das personagens femininas (Lightning e Vanille) depreciam o trabalho que fazem ao longo do jogo: apesar de saber que está sacrificando sua vida para evitar mortes, Vanille avalia-se como covarde e assassina; e Lightning afirma que Snow é o herói que a convenceu de que sua irmã poderia ser salva e que fez de Hope uma pessoa mais forte, apesar de ter sido ela a cuidadora, incentivadora e treinadora do menino durante o jogo. Há, pois, expectativas de desempenho de papéis tradicionais em relação às mulheres como, por exemplo, a prestação de cuidados (o que não se espera das personagens masculinas). Lightning e Hope começam em desconformidade com seus papéis tradicionais de gênero (ela sem demonstrar afeto; ele a surgir como frágil e dependente) e terminam em 
conformidade com as expectativas de gênero (ela afetuosa; ele independente e corajoso).

É importante destacar que, embora todas as personagens exerçam protagonismo ao longo da trama e haja uma protagonista feminina, verifica-se predominantemente o exercício de papéis tradicionais por parte das personagens integrantes da narrativa, o que está de acordo com inúmeros estudos que têm mostrado que ainda não há uma equidade a este nível entre as personagens femininas e masculinas (e.g., Burgess et al. 2007; Jansz e Martis 2007; Martins et al. 2009). Por exemplo, a comentarista cultural Anita Sarkeesian pesquisou os principais papéis desempenhados pelas personagens femininas nos videojogos baseados naqueles que são tradicionalmente usados em outras mídias. Sua pesquisa resultou em uma série de vídeos intitulados Tropes vs Women in Videogames, publicados no website Feminist Frequency ${ }^{6}$, entre 2013 e 2014, revelando os seguintes papéis: donzela

\footnotetext{
${ }^{6}$ www.feministfrequency.com

7 Exemplos: Princesa Peach (de Super Mario Bros); Princesa Leia (Star Wars - Episódio 4); Alena Vorshevsky (Call of Duty: Modern Warefare 3); Yuna (Final Fantasy X).
}

108 em perigo (i.e., a personagem não tem capacidade para sair de uma situação por si mesma e precisa ser salva) ${ }^{7}$; Ms Male Character (i.e., a personagem é conhecida apenas em virtude da relação que estabelece com um homem como, por exemplo, a $\left.\mathrm{Sr}^{\mathrm{a}} \mathrm{Pac}-\mathrm{Man}\right)$; síndrome de personalidade feminina em que a personagem é a única mulher em um grupo de homens, sendo esta a única característica que a define, como a Princesa Peach de Super Mario; e a "dama na geladeira", que é a morte de uma mulher como estopim para a ação ${ }^{8}$. FFXIII apresenta dois desses clichês narrativos: as donzelas em perigo, isto é, Serah (que se transforma em cristal no começo do game) e Vanille (que Fang tenta evitar que se torne um monstro), e a dama no refrigerador, ou seja, Nora (mãe de Hope, que morre logo no início e serve de estopim para o envolvimento dele na trama). Há a variação de ter o filho de Sazh em perigo, mas a maioria de resgates é de mulheres.

\section{Considerações finais}

\footnotetext{
${ }^{8}$ Esposas e/ou filhas mortas e homens em busca de vingança em games: God of War, Max Payne, Red Dead Redemption. Em filmes: Código de Conduta (Law Abiding Citizen), Sin City - A cidade do pecado, O Justiceiro (The Punisher).
} 
$\mathrm{O}$ presente estudo visou compreender o modo como as personagens femininas são construídas e representadas no RPG Final Fantasy XIII, a partir da observação das suas dimensões construtivas (Sheldon, 2004; Isbister, 2006; Zagalo, 2009; Teixeira, 2013), bem como auscultar em que medida este processo se articula com a veiculação de estereótipos e papéis tradicionais de gênero. Buscou-se inquirir as construções e representações de gênero que ainda são um tema importante a ser estudado por se repercutirem em formas de segregar pessoas a partir de um suposto fator biológico que limita o ser humano a determinados traços e papéis sociais (Nogueira, 2004).

$\mathrm{Na}$ construção de personagens mais complexas, os/as produtores/as procuraram desenvolver a narrativa a partir de diferentes ângulos, visto que no jogo se pode jogar com todas as personagens e conhecer um pouco melhor suas histórias. Apesar disso, algumas personagens femininas (Vanille e Fang) não tiveram um passado tão claro, o que é um requisito importante para a construção de uma personagem complexa. FF XIII distribuiu bem as habilidades de luta (de distância ou contato), pois todas as personagens eram genericamente capazes de causar um bom número de dano no inimigo, o que não acontecia em outros títulos da série, tais como o FF X (Kanaan, 2015): as personagens femininas tinham apenas a opção de ataques à distância com magia para causar dano e ataques de contato que quase não tiravam pontos de vida (HP). Na distribuição de papéis de cura, as personagens femininas constituíram a maioria; as personagens masculinas dominaram nos papéis de proteção da equipe.

Os resultados indicam que a construção das personagens de videojogos é baseada maioritariamente nos estereótipos tradicionais de gênero: a maior parte das mulheres exibe traços físicos que correspondem à feminilidade normativa (e.g., mais baixas, bonitas, jovens e com o vestuário reduzido). A maioria das mulheres adultas tem traços de bebê (o que não acontece com os homens adultos) e exibe características de personalidade e habilidades comummente associadas ao estereótipo feminino (e.g., maternalidade, sensibilidade e habilidades de cura), enquanto as personagens masculinas 
mostram poucos desses mesmos traços.

Verifica-se ainda a existência de uma personagem disposta ao autossacrifício (tradicionalmente esperado das mulheres); a adequação de comportamentos que no início do jogo destoavam dos papéis tradicionais (Lightning torna-se afetuosa e Hope corajoso) e a desvalorização do seu próprio trabalho por parte das personagens femininas.

A construção de personagens baseadas em estereótipos tradicionais de gênero pode ser um obstáculo à aproximação e à legitimação das mulheres como jogadoras em uma indústria que ainda vê o seu público-alvo como maioritariamente masculino e perpetua uma representação que pode ser prejudicial para a autoimagem das próprias mulheres, da imagem que os homens fazem das mulheres e da imagem que eles fazem deles mesmos. Há jogos blockbuster, como Metroid e Mirror's Edge, que trazem mulheres como protagonistas sem recorrer aos estereótipos tradicionais de gênero e

\section{9}

http://www.techtudo.com.br/listas/noticia/2016/ 04/saudades-de-metroid-veja-curiosidades-epolemicas-da-franquia.html, http://www.ign.com/articles/2008/08/15/ign- conquistaram o público. No caso de Metroid, Samus Aran foi uma das primeiras protagonistas na plataforma de jogos da Nintendo, em $1986^{9}$, e surpreendeu o público quando somente ao completar o jogo se descobria que ela era mulher (Roberts, 2012). Mirror's Edge (com um título lançado em 2008 e outro em 2016) conta a história de Faith, que usa movimentos de parkour para atingir seus objetivos, tendo obtido críticas positivas ${ }^{10}$.

Embora esteja limitado às personagens de apenas um dos títulos Final Fantasy e circunscrito ao gênero RPG, este estudo permite mostrar que a construção das personagens - apesar de totalmente digitais - é baseada em pressupostos que não contemplam a diversidade do público de videojogos. Entre as possibilidades que se abrem com a análise das personagens de videojogos em seus aspetos construtivos, está a compreensão dos estereótipos e dos papéis de gênero que a indústria de games (re)constrói, no sentido de fomentar a produção de jogos que ttp://gamers.com/feature/egmtop100/index.jsp. 10 http://www.metacritic.com/game/xbox360/mirrors-edge-2008. 
transcendam o padrão hegemônico masculino (Fron et al, 2007) e apresentem personagens femininas diversas, com as quais as jogadoras possam se identificar (Isbister, 2006; Vermeulen et al, 2011).

\section{Referências bibliográficas}

Amâncio, Lígia (1998), Masculino e feminino: a construção social da diferença. Porto: Afrontamento.

Bardin, Laurence (1977), Análise de Conteúdo, S/L: Edições 70.

Bonvillain, Nancy (1995), Women and men: cultural constructs of gender. New Jersey: Prentice-Hall.

Burgess, Melinda. C. R; Stermer, Steven P.; Burgess, Stephen R. (2007), “Sex, Lies, and Video Games: The Portrayal of Male and Female Characters on Video Game Covers", Sex Roles 57(5), 419433. Consultado a 31.10.2013 em http://link.springer.com/article/10.1007 \%2Fs11199-007-9250-0

Cerqueira, Carla (2008), “A Imprensa e a Perspectiva de Género. Quando elas são notícia no Dia Internacional da
Mulher", Observatorio (OBS*) Journal 5, 2(2), 139-164. Consultado a 16.09.2014 em http://obs.obercom.pt/index.php/obs/arti cle/view/101/153.

Dill, Karen. E.; Thill, Kathryn P. (2007), "Video Game Characters and the Socialization of Gender Roles: Young People's Perceptions Mirror Sexist Media Depictions", Sex Roles 57(11), 851-864. Consultado a 16.09.2014 em http://link.springer.com/article/10.1007 \%2Fs11199-007-9278-1\#page-1.

Entertainment Software Association (2011), “2011 Sales, Demographic And Usage Data”. Consultado a 01.10.2014 em

http://www.isfe.eu/sites/isfe.eu/files/atta chments/esa_ef_2011.pdf.

Entertainment Software Association (2014), “2014 Sales, Demographic And Usage Data”. Consultado a 01.10.2014 em www.theesa.com/wpcontent/uploads/2014/10/ESA_EF_201 4.pdf.

Entertainment Software Association (2015), “2015 Sales, Demographic And 
Usage Data”. Consultado a 20.01.2016 em http://www.theesa.com/wpcontent/uploads/2015/04/ESA-

Essential-Facts-2015.pdf.

Fron, Janine; Fullerton, Tracy; Morie, Jacquelyn F.; Pearce, Celia (2007), “The Hegemony of Play", Proceedings of DiGRA 2007: Situated Play, 4, 309-318. $\begin{array}{llll}\text { Consultado a } & 08.10 .2014 & \mathrm{em}\end{array}$ http://www.digra.org/digitallibrary/publications/the-hegemony-ofplay/

Gill, Rosalind (2010), Gender and the media. Cambridge: Polity.

Isbister, Katherine (2006), Better Game Characters by Design: A Psychological Approach. São Francisco: Morgan Kaufmann Publishers.

Jansz, Jeroen; Martis, Raynel. G. (2007), "The Lara Phenomenon: Powerful Female Characters in Video Games", Sex Roles, 56(3), 141-148. Consultado a 31.10 .2013 em http://link.springer.com/article/10.1007 \%2Fs11199-006-9158-0.
Jenkins, Henry (2006), Fans, bloggers, and gamers: exploring participatory culture. Nova York: New York University Press.

Jørgensen, Kristine (2010), “Game Characters as Narrative Devices. A Comparative Analysis of Dragon Age: Origins and Mass Effect 2", Eludamos Journal for Computer Game Culture, 4 (2), 315-331. Consultado a 13.10.2014 em

www.eludamos.org/index.php/eludamos /rt/printerFriendly/vol4no2-13/192.

Kanaan, Luísa (2015), Entre o báculo mágico e a espada: Representações das personagens femininas em Final Fantasy $X$ e XIII. Universidade do Minho, Instituto de Ciências Sociais. Braga. Dissertação de Mestrado.

Koster, Raph (2005), A Theory of Fun for Game Design. Scottsdale: Paraglyph Press.

Kuittinen, Jussi; Holopainen, Jussi (2009), "Some Notes on the Nature of Game Design", Proceedings of DiGRA 2009 Breaking New Ground: Innovation in Games, Play, Practice and Theory, 5, 
2-8. Consultado a 03.10.2014 em http://www.digra.org/wpcontent/uploads/digitallibrary/09287.49313.pdf.

Lazzaro, Nicole (2004), "Why We Play Games: The Four Keys to Player Experience", XEODesign, Game Developers Conference 2004. Consultado a 30.09.2014 em http://www.xeodesign.com/xeodesign_ whyweplaygames.pdf.

Levis, Diego (1997), Los videojuegos, un fenómeno de masas: qué impacto produce sobre la infancia y la juventud la industria más próspera del sistema audiovisual. Barcelona: Paidós.

Martins, Nicole; Williams, Dmitri C.; Harrison, Kristen; Ratan, Rabindra A. (2009), "A Content Analysis of Female Body Imagery in Video Games", Sex Roles, 61, 824-836. Consultado a 31.10 .2013 em http://link.springer.com/article/10.1007 \%2Fs11199-009-9682-9\#page-1.

Newman, James (2004), Videogames. London: Routledge.
Nieborg, David B. (2011), "The winner takes all: Standardization and console games", Proceedings of DiGRA 2011 Conference: Think Design Play, 6, 1-14. $\begin{array}{llll}\text { Consultado a } & 09.10 .2014 & \mathrm{em}\end{array}$ www.digra.org/digitallibrary/publications/the-winner-takesall-standardization-and-console-games/. Nogueira, Conceição (2004), “Ter ou fazer o género: o dilema das opções metodológicas na psicologia social", in Neuza Maria de Fátima Guareschi (org.), Estratégias de invenção do presente: a psicologia social no contemporâneo. Porto Alegre: EDIPUCRS, 249-284. Consultado a 01.01.2015 em http://hdl.handle.net/1822/5503.

Pérez-Latorre, Óliver (2012), “Del Ajedrez a StarCraft. Análisis comparativo de juegos tradicionales $\mathrm{y}$ videojuegos", Comunicar Revista Científica de Educomunicación, 38(XIX), 121-129. Consultado a 16.09.2014 em www.revistacomunicar.com/index.php? contenido $=$ detalles $\&$ numero $=38 \&$ articu $l o=38-2012-15$. 
Roberts, Katherine (2012), “A sociological exploration of a female character in the Metroid videogames series", The Computer Games Journal, special edition, 82-112. Consultado a 10.09 .2016

em https://www.researchgate.net/publicatio n/235745133_A_sociological_explorati on_of_a_female_character_in_the_Metr oid_videogames_series.

Sarkeesian, Anita (2013), "Tropes vs Women in Video Games", Página $\begin{array}{llll}\text { consultada a } & 01.02 .2015 & \mathrm{em}\end{array}$ www.feministfrequency.com.

Sheldon, Lee (2004), Character Development and Storytelling for Games. Boston: Thomson Course Technology PTR.

Teixeira, Pedro Mota (2013), A Representação Emocional da Personagem Virtual no Contexto da Animação Digital: do Cinema de Animação aos Jogos Digitais. Universidade do Minho, Instituto de Ciências Sociais. Braga. Tese de Doutoramento.

Van Zoonen, Liesbet (2006/1994), Feminist media studies, London: Sage.
Vermeulen, Lotte et al. (2011), "You Are What You Play? A Quantitative Study into Game Design Preferences across Gender and their Interaction with Gaming Habits", Proceedings of DiGRA 2011 Conference: Think Design Play, 6, 1-20. Consultado a 14.10.2014 em http://www.digra.org/wpcontent/uploads/digitallibrary/11313.31106.pdf.

Zagalo, Nelson (2009), Emoções Interactivas, do Cinema para os Videojogos. Braga: Grácio Editor.

Zagalo, Nelson (2013), “A singularidade da linguagem dos videojogos", Portal de la Comunicación InCom. Universidade Autónoma de Barcelona. Consultado a 10.02 .2014

em www.portalcomunicacion.com/leccione s_det.asp?id=83. 